Abstracta Iranica Abstracta Iranica

Revue bibliographique pour le domaine irano-aryen

Volume 32-33 | 2013

Comptes rendus des publications de 2009-2010

\title{
John Curtis, St John Simpson (eds.). The world of Achaemenid Persia
}

History, Art and Society in Iran and the Ancient Near East, Proceedings

of a Conference at the British Museum $29^{\text {th }}$ September $-1^{\text {st }}$ October 2005

\section{Astrid Nunn}

\section{(2) OpenEdition}

1 Journals

Édition électronique

URL : http://journals.openedition.org/abstractairanica/40223

DOI : $10.4000 /$ abstractairanica.40223

ISSN : 1961-960X

Éditeur :

CNRS (UMR 7528 Mondes iraniens et indiens), Éditions de l'IFRI

Édition imprimée

Date de publication : 1 décembre 2013

ISSN : 0240-8910

Référence électronique

Astrid Nunn, « John Curtis, St John Simpson (eds.). The world of Achaemenid Persia », Abstracta Iranica [En ligne], Volume 32-33 | 2013, document 49, mis en ligne le 01 juillet 2016, consulté le 05 octobre 2020. URL : http://journals.openedition.org/abstractairanica/40223 ; DOI : https://doi.org/10.4000/ abstractairanica.40223

Ce document a été généré automatiquement le 5 octobre 2020.

Tous droits réservés 


\section{John Curtis, St John Simpson (eds.). The world of Achaemenid Persia}

History, Art and Society in Iran and the Ancient Near East, Proceedings of a Conference at the British Museum $29^{\text {th }}$ September $-1^{\text {st }}$ October 2005

\section{Astrid Nunn}

\section{RÉFÉRENCE}

John Curtis, St John Simpson (eds.). The world of Achaemenid Persia. History, Art and Society in Iran and the Ancient Near East, Proceedings of a Conference at the British Museum $29^{\text {th }}$ September $-1^{\text {st }}$ October 2005. London, I.B. Tauris in partnership with Iran Heritage Foundation, 2010, 626 p., nbres ill., bibliographie et index communs.

1 La publication de la conférence tenue au British Museum en 2005, à l'occasion de l'exposition " Forgotten Empire, The world of Ancient Persia », a abouti à une splendide publication qui en incluant tous les aspects d'une civilisation et son expansion régionale, reflète bien le titre «the world of Achaemenid Persia ». Les cinquante et un articles, dont six ne sont que des résumés, sont regroupés en huit thèmes comportant entre trois et dix contributions; quelques-unes seulement sont signalées individuellement ici, comme exemples de la diversité des sujets abordés dans les thèmes : « History and Historiography », « Religion » (cf. c.r. n 33), « Gender Studies » (cf. c.r. $\mathrm{n}^{\circ}$ 44), «Art and Architecture » (cf. c.r. $\mathrm{n}^{\circ}$ 109), « Regional Studies » (cf. c.r. $\left.\mathrm{n}^{\circ} 72\right)$.

Conformément au titre, le contenu de l'ouvrage concerne d'abord la Perse achéménide et surtout Persépolis, pour les représentations (bas-reliefs, sceaux). Les œuvres et documents issus des autres parties de l'empire sont abordés au travers des différents thèmes, en particulier par les sceaux d'une part et par des contributions dans le chapitre « Regional Studies » d'autre part. Comme souvent dans les ouvrages collectifs, les réelles nouveautés ou les mises au point importantes sont un peu noyées parmi des contributions plus de circonstance. Le spécialiste devra chercher par lui-même les idées 
ou informations véritablement nouvelles. L'ensemble apportera des éclairages intéressants pour le lecteur généraliste qui trouvera des présentations des aspects multiples de l'empire achéménide.

3 On se borne à noter ici deux articles qui se recoupent avec les contributions d'A. Caubet et N. Daucé dans la publication de J. Perrot, «Le palais de Darius à Suse » (c.r. $\mathrm{n}^{\circ}$ 105). $\mathrm{S}$. Maras a réétudié les briques de Suse conservées au Louvre. Après une courte introduction sur les briques à glaçure en Elam, elle considère le programme iconographique. Darius a combiné les thèmes perses de Persépolis et babyloniens de Babylone et ainsi manifesté son contrôle sur ces deux cultures. Ayant eu les briques en main, l'A. analyse en détail les marques d'artisans. Il est intéressant de noter que certaines sont des lettres araméennes et lyciennes, qui, elles aussi, sont la preuve d'une koinê, cette fois-ci non stylistique mais ethnique.

4 L'article d'A. Caubet rassemble tous les objets en matières vitreuses de l'époque achéménide : la décoration architecturale en briques vernissées, la vaisselle de table en faïence qui imite des formes métalliques ainsi que des amulettes en faïence et de formes égyptiennes. Une statuette de Bès découverte à Amrit est rentrée au Louvre en 1860. Un fragment de figure féminine trouvée à Suse est probablement égyptien. La statuette mesurait à l'origine environ $50 \mathrm{~cm}$, taille exceptionnellement grande pour cette technique. En résumé, le style de ces objets est si international, qu'il est impossible d'en définir l'origine. Ils font en tout cas preuve d'un très haut niveau technique et esthétique.

\section{AUTEURS}

\section{ASTRID NUNN}

Université de Munich 